\title{
A study to assess knowledge and attitude of antenatal women about maternal nutrition attending a tertiary care centre
}

\author{
Renu Gupta*, Shaily Agarwal, Neetu Singh, Rimjhim Jain, Arti Katiyar, Almas siddiqui
}

Department of Obstetrics and Gynaecology, GSVM Medical College Kanpur, Uttar Pradesh, India

Received: 8 March 2016

Accepted: 4 April 2016

\section{*Correspondence:}

Dr. Renu Gupta,

E-mail: drrenu22404@gmail.com

Copyright: ( ) the author(s), publisher and licensee Medip Academy. This is an open-access article distributed under the terms of the Creative Commons Attribution Non-Commercial License, which permits unrestricted non-commercial use, distribution, and reproduction in any medium, provided the original work is properly cited.

\section{ABSTRACT}

Background: Nutrition is the fundamental pillar of human life. All human beings need a balanced amount of nutrients for proper functioning of body system. Inadequate nutrition during pregnancy has a negative impact on the pregnant mother as well as short and long term consequences on the newborn. This study aims to assess knowledge and attitude of antenatal women about maternal nutrition in pregnancy and highlights the need of interventions aimed at promoting awareness about healthy diet during pregnancy in association with various socio demographic factors.

Methods: This study was conducted on 850 antenatal women attending the antenatal clinic of UISEMH, Kanpur, Uttar Pradesh, India from August 2015 to February 2016. A 25 point- 10 minute questionnaire was designed to collect information about awareness and myths associated with nutrition in pregnancy from antenatal women.

Results: Only $22 \%$ of the women had good knowledge about nutrition during pregnancy and $82 \%$ showed willingness to acquire more information about maternal nutrition. Source of information for most pregnant women were immediate family members (41\%). Most women were lacking in their knowledge about common local sources of nutrition, adequate weight gain during pregnancy and effects of over and under nutrition.

Conclusions: There is need to impart more knowledge to pregnant women about nutrition in pregnancy. More attention should be paid on nutritional guidance among pregnant women especially in young and less well educated women for healthy outcome of mother and babies. This study emphasizes the importance of dietary counselling by attending doctors as an integral part of antenatal care.

Keywords: Maternal nutrition, Willingness to acquire more information

\section{INTRODUCTION}

Pregnancy is no doubt a very exciting time; but it is also a period of great physiological stress for the woman as she is nurturing a growing foetus in her body. Foetal development is accompanied by many physiological, biochemical and hormonal changes occurring in maternal body, which influence the need for nutrients and the efficiency with which the body uses them. Nutrition is the fundamental pillar of human life. ${ }^{1}$ All human beings need a balanced amount of nutrients for proper functioning of body system. It is well documented that inadequate nutrition during pregnancy results in increased risk of adverse consequences like IUGR, LBW, preterm birth, prenatal and intranatal mortality. Moreover, excessive intake of nutrients during pregnancy can also lead to complications like PET, GDM, macrosomia, dystocia and higher prevalence of caesarean section. ${ }^{2}$ Thus, inadequate or excessive nutrition during pregnancy has a negative impact on the pregnant mother as well as short and long term consequences on the newborn. ${ }^{3}$

Pregnant women are highly receptive towards advice on their nutrition and lifestyle as it sure has a direct impact on the health of the offspring. Thus, pregnancy is the optimum time to educate women regarding their requirement of nutrition and balanced diet in order to prevent any short and long term consequences on their own and their offspring's health. Still it is known that the incidence of dietary inadequacies as a result of dietary 
habits and patterns in pregnancy is higher during pregnancy than at any other stage of the life cycle. ${ }^{4}$

This study aims to highlight the need of interventions aimed at promoting awareness about healthy diet during pregnancy to improve the overall outcome of pregnancy.

\section{METHODS}

It was a cross sectional study conducted on 850 antenatal women from August 2015 to February 2016. A 25 point10 minute questionnaire was designed to collect information about awareness and myths associated with nutrition in pregnancy from pregnant women attending the antenatal clinic of UISEMH, Kanpur, India (Table 1).

Table 1: Dietary questionnaire included the following topics.

\section{Topics}

Demographic information about age, SES, parity, habitat and inter pregnancy interval

Knowledge about nutrition in pregnancy

Source of information

Willingness to get more knowledge about healthy lifestyle

Detailed knowledge about local sources of carbohydrates and proteins and iron

Knowledge about government schemes for nutrition in pregnant women

Awareness about harmful effects of addiction and substance abuse

Knowledge about adequate weight gain during pregnancy

Knowledge about harmful effects of over or under nutrition during pregnancy

Significance of acquiring knowledge about nutrition in pregnancy

Type of information considered most useful by the women

All pregnant women attending antenatal clinic at UISEMH were the candidates of our study. Our tertiary care center is situated in the urban area of Kanpur and has inflow of patients from nearby rural and urban areas.

These pregnant women were well explained about the study briefly and were given a 25 point $10 \mathrm{~min}$ questionnaire to be filled by them while awaiting their antenatal checkup in the clinic. The questions were designed in easily apprehensible local language. The illiterate patients were aided by the junior residents who read the questionnaire to them without giving any hint or leading answers and marked their responses.

\section{RESULTS}

A total of 850 pregnant women were given the questionnaire. The questionnaire was completed by 788 women. A total of $78 \%$ women belonged to age group of 20 to 30 years. $42 \%$ of the women were primigravida, $36 \%$ were Second Gravida while $22 \%$ were more than Gravida 2. Majority of women belonged to low socioeconomic status according to Modified Kuppuswami Classification. 51\% of the women had inter pregnancy interval of 1-2 years while only $20 \%$ had $>2$ years interval from last pregnancy. Most of the women $(72 \%)$ belonged to rural area (Table 2).

Table 2: Socio-demographic variables of the study population.

\begin{tabular}{|lr|}
\hline Age (years) $<20$ & $5 \%$ \\
\hline $20-25$ & $36 \%$ \\
\hline $25-30$ & $42 \%$ \\
\hline$>30$ & $17 \%$ \\
\hline Parity & $42 \%$ \\
\hline G1 & $36 \%$ \\
\hline G2 & $22 \%$ \\
\hline G $>3$ & $9 \%$ \\
\hline SES (Modified Kuppuswami classification) \\
\hline Class 1 & $12 \%$ \\
\hline Class 2 & $26 \%$ \\
\hline Class 3 & $34 \%$ \\
\hline Class 4 & $19 \%$ \\
\hline Class 5 & $29 \%$ \\
\hline Inter pregnancy interval (in years) \\
\hline$<1$ & $51 \%$ \\
\hline $1-2$ & $20 \%$ \\
\hline$>2$ & $28 \%$ \\
\hline Habitat & $72 \%$ \\
\hline Urban & \\
\hline Rural & \\
\hline
\end{tabular}

Only $22 \%$ of the women had good knowledge about nutrition during pregnancy, $42 \%$ had average knowledge while $36 \%$ of women had poor knowledge about nutrition and healthy lifestyle during pregnancy. This categorization was based on their total score obtained in the questionnaire and a score of 0-4 was considered as no knowledge, 5-10 little knowledge and >10 was considered as good knowledge (Table 3 ).

Source of information for pregnant women was mainly family members (38\%) and a very few acquired adequate information from their doctors (11\%) or ANMs (18\%). The source of information for most rural women was their immediate family members while urban women also gained some knowledge from books, newspapers and internet. But in both cases, the role of attending doctors and local health workers in nutritional guidance was very less (Table 3). 
Table 3: Dietary results.

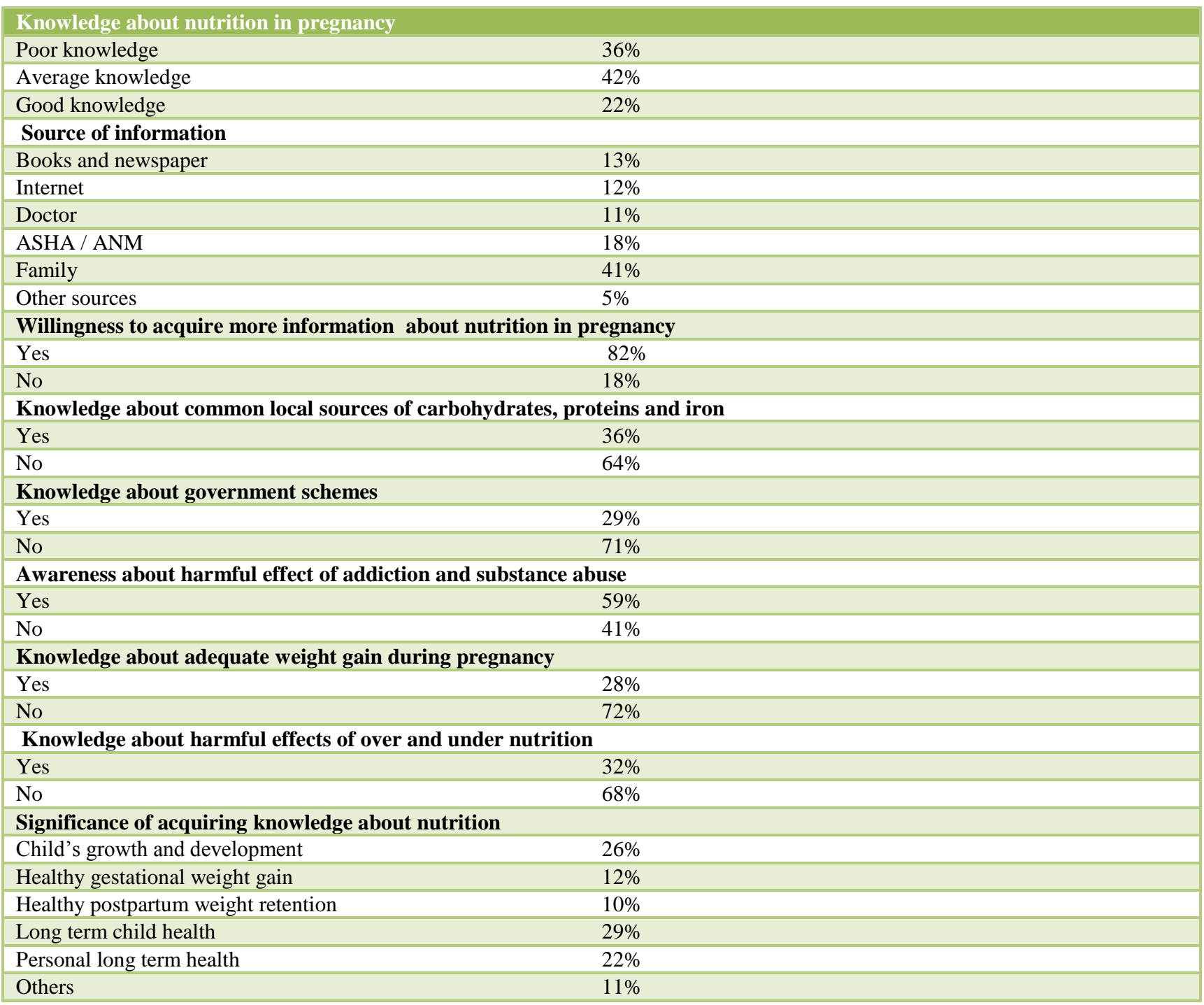

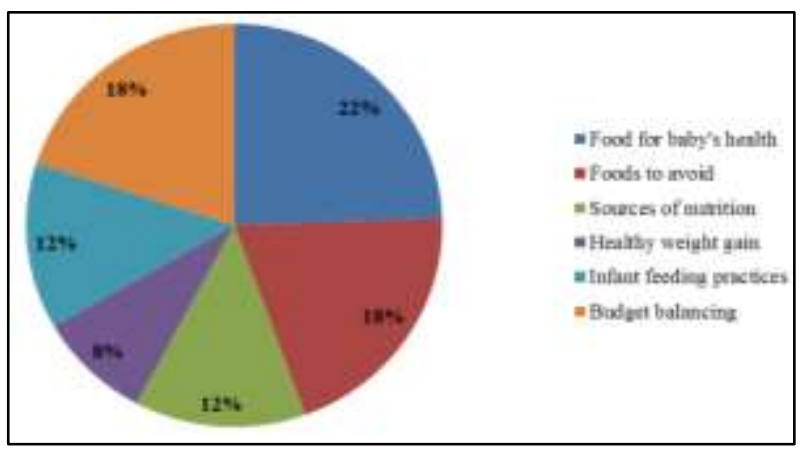

Figure 2: Information considered most useful by pregnant women.

Out of all the participants, $82 \%$ showed willingness to acquire more information about nutrition especially related to the importance of food for baby's health (22\%), foods to avoid during pregnancy (18\%), sources of nutrition $(12 \%)$, healthy weight gain $(8 \%)$ and infant feeding practices (12\%) and balancing budget with nutrition (18\%) (Figure 1). Very few women had knowledge about common local sources of nutrition (36\%), adequate weight gain during pregnancy (28\%) and effects of over and under nutrition (32\%). Many women were aware about the harmful effects of smoking, addiction and substance abuse during pregnancy (59\%) (Table 3). There was very little knowledge among pregnant women about government policies and schemes to promote health and nutrition during pregnancy (29\%) (Table 3).

\section{DISCUSSION}

Despite consistent plea in literature for interventions that target excessive weight gain or inadequate weight gain during pregnancy, not many studies have been undertaken to assess the knowledge of pregnant women and the information channels used by them to increase their awareness about nutrition. Thus, the purpose of this 
study was to examine the current knowledge of nutrition in pregnancy among pregnant women.

In our study, only $22 \%$ of the women had good knowledge about nutrition during pregnancy, $42 \%$ had average knowledge while $36 \%$ of women had poor knowledge about nutrition and healthy lifestyle during pregnancy. Similarly a study conducted in Malawi by Naomi found that only two thirds $(70 \%)$ of the pregnant women had some knowledge on nutrition and food groups in pregnancy. ${ }^{5}$ This low nutritional knowledge may be due to low income and low educational status of the study participants. The incidence of dietary inadequacies as a result of dietary habits and patterns in pregnancy is higher during pregnancy than at any other stage of the life cycle. ${ }^{4}$

Very few women in the study group had knowledge about common local sources of nutrition (36\%) and adequate weight gain during pregnancy (28\%). Similarly, a study conducted Malawi, Lilongwe also found that most of the women $(60 \%)$ said that eating from all food groups is good for a woman's health and for foetal growth and development. ${ }^{5}$ Also in a study conducted in America at El-Menshawy hospital found that about half of the women didn't have enough knowledge regarding the meaning, the importance and the constituents of a well-balanced diet for the pregnant women. However, a study reported by Latifa et al concluded that $61.3 \%$ of pregnant mother had good knowledge about the sources of iron and $71.8 \%$ knew the sources of calcium during pregnancy. $^{6}$

Only $32 \%$ of the pregnant women in the study group had knowledge about the effects of over and under nutrition and $59 \%$ had awareness about the harmful effects of smoking, addiction and substance abuse during pregnancy. Similarly, a study conducted in America at El-Menshawy hospital found that many women in the study lacked the awareness of the consequences of inadequate nutrition during pregnancy on mother and foetus. ${ }^{6}$ Source of information for most pregnant women was their family members $(38 \%)$ and a very few acquired adequate information from their attending doctors $(20 \%)$ or ANMs (5\%). Nutrition knowledge of employed women in a study conducted in Malay pregnant women was mainly explained by more access to internet, books and magazines as source of information in work area. ${ }^{7}$

\section{CONCLUSIONS}

The study highlights that despite so many schemes and policies run by the government to promote nutrition among pregnant women, the awareness among pregnant women about the role of adequate nutrition, constituents and sources of balanced diet and the consequences of over and under nutrition is still inadequate. The primary source of whatever knowledge they had about maternal nutrition was mainly from family members, but the role of local health workers and attending doctors in nutritional counselling during antenatal period was very less. So there is need to impart more knowledge to pregnant women about nutrition in pregnancy and more attention should be paid on nutritional guidance among pregnant women especially as regards young and less well educated women for healthy outcome of women and their children.

Funding: No funding sources

Conflict of interest: None declared

Ethical approval: The study was approved by the Institutional Ethics Committee

\section{REFERENCES}

1. World Bank (2006) Repositioning Nutrition as central to development: A strategy for large scale action, The International Bank for Reconstruction and Development, World Bank, Washington DC, USA.

2. Rocco PL, Orbitello B, Perini L, Pera V, Ciano RP, Balestrieri M. Effects of pregnancy on eating attitudes and disorders: a prospective study. J Psychosom Res. 2005;59:175-9.

3. Westenberg L, van der Klis KA, Chan A, Dekker G, Keane RJ. Aboriginal teenage pregnancies compared with non-Aboriginal in South Australia 1995- 1999. Aust N Z J Obstet Gynaecol. 2002;42:187-92.

4. Rao A, Sahoo S, Basumati P. A study of nutritional status of pregnant women of some villages in Balasore district, Orissa. J Hum Ecol. 2006;20:227-32.

5. Naomi M. Investigating health and nutrition messages given to pregnant women at bwaila hospital in Lilongwe; master thesis; food, nutrition and health; 2010.

6. Latifa MF, Manal HA, Nihal SS. Nutritional awareness of women during pregnancy. J American Sci. 2012;8(7):494-502.

7. Mitra M, Wan A, Manan W, Affizal A, Mohd S Dietary Knowledge and Behaviors in a Sample of Malay Pregnant Women; UMT $11^{\text {th }}$ International annual symposium on sustainability science and management $09^{\text {th }}-11^{\text {th }}$ July 2012, Terengganu, Malaysia; 2012.

Cite this article as: Gupta $\mathrm{R}$, Agarwal S, Singh N, Jain R, Katiyar A, Siddiqui A. A study to assess knowledge and attitude of antenatal women about maternal nutrition attending a tertiary care centre. Int J Reprod Contracept Obstet Gynecol. 2016:5:1549-52. 